\title{
Correspondence \\ Nitric Oxide Synthase Mediation of Darbepoetin's Cognitive Benefits: A Paradoxical Effect?
}

\author{
Ganesan Venkatasubramanian*,I \\ 'The Metabolic Clinic in Psychiatry, Department of Psychiatry, National Institute of Mental Health and Neurosciences, Bangalore, India
}

Neuropsychopharmacology (2012) 37, 1074; doi:I0.1038/npp.20II.270

Recently, Kajitani et al (2010) reported observations to support that enhanced nitric oxide signaling might be the mechanistic basis for erythropoietin's cognitive benefits in schizophrenia. However, numerous studies have suggested that enhanced nitric oxide signaling might adversely impact schizophrenia. For example, increased nitric oxide signaling has been demonstrated to underlie the information-processing deficits in the phencyclidine model of schizophrenia (Palsson et al, 2010); intriguingly, the nitric oxide synthase inhibitor ( $\mathrm{N}(\mathrm{G})$-nitro-L-arginine methyl ester (L-NAME)) used by the authors in this study (Kajitani et al, 2010) has been reported to ameliorate the phencyclidine-induced cognitive deficits (Klamer et al, 2001). Moreover, treatment with minocycline, a nitric oxide synthase inhibitor, improved cognitive deficits in schizophrenia patients in a double-blind, randomized, placebo-controlled study (Levkovitz et al, 2010). Also, neuronal nitric oxide synthase haplotype association with schizophrenia has been speculated as an instance of increased predisposition towards this devastating disorder, yet also improving cognitive domains (Reif et al, 2006). Contextually, it is important to note that the beneficial effects of erythropoietin on cognitive deficits in schizophrenia have been demonstrated in patients that were stabilized with antipsychotic treatment; these patients did not have severe positive symptoms (Ehrenreich et al, 2007). If the enhanced nitric oxide signaling is indeed the predominant mechanistic basis for erythropoietin's benefits (Kajitani et al, 2010), then, this is an issue of concern because of the potential of this mechanism to worsen schizophrenia symptoms - perhaps with long-term use.

\section{ACKNOWLEDGEMENTS}

GV is supported by the Wellcome Trust/DBT India Alliance senior fellowship research grant.

\section{DISCLOSURE}

The author declares no conflict of interest.

\section{REFERENCES}

Ehrenreich H, Hinze-Selch D, Stawicki S, Aust C, Knolle-Veentjer S, Wilms $S$ et al (2007). Improvement of cognitive functions in chronic schizophrenic patients by recombinant human erythropoietin. Mol Psychiatry 12: 206-220.

Kajitani K, Thorne M, Samson M, Robertson GS (2010). Nitric oxide synthase mediates the ability of darbepoetin alpha to improve the cognitive performance of STOP null mice. Neuropsychopharmacology 35: 1718-1728.

Klamer D, Engel JA, Svensson L (2001). The nitric oxide synthase inhibitor, L-NAME, block phencyclidine-induced disruption of prepulse inhibition in mice. Psychopharmacology (Berl) 156: 182-186.

Levkovitz Y, Mendlovich S, Riwkes S, Braw Y, Levkovitch-Verbin H, Gal G et al (2010). A double-blind, randomized study of minocycline for the treatment of negative and cognitive symptoms in early-phase schizophrenia. J Clin Psychiatry 71: 138-149.

Palsson E, Lowry J, Klamer D (2010). Information processing deficits and nitric oxide signalling in the phencyclidine model of schizophrenia. Psychopharmacology (Berl) 212: 643-651.

Reif A, Herterich S, Strobel A, Ehlis AC, Saur D, Jacob CP et al (2006). A neuronal nitric oxide synthase (NOS-I) haplotype associated with schizophrenia modifies prefrontal cortex function. Mol Psychiatry 11: 286-300.
*Correspondence: Dr G Venkatasubramanian, The Metabolic Clinic in Psychiatry, Department of Psychiatry, National Institute of Mental Health and Neurosciences, Bangalore 560029, India, Tel: +00 9| 80 26995256, Fax: +0091 8026564830 ,

E-mail: venkat.nimhans@yahoo.com 